\title{
Data and Reflections on Access-Transition to Higher Education in Portugal
}

\author{
João Baptista, Cristina Sin, and Orlanda Tavares
}

\section{INTRODUCTION}

This chapter aims to analyse inequalities in the transition from upper secondary to higher education in Portugal, using empirical data from the General-Directorate of Education and Science Statistics (DGEEC). It argues that educational inequalities are already present in Portuguese students' trajectories before higher education and that the transition to higher education therefore reflects these different opportunities.

Similar to other countries where widening access to higher education became a political objective meant to foster social justice and economic development (OECD, 2008), in Portugal, following the democratic revolution of 1974, it was believed that the massification of higher education

J. Baptista $(\bowtie)$

Direção-Geral de Estatísticas da Educação e Ciência (DGEEC), Lisbon, Portugal C. Sin $\bullet$ O. Tavares

Agency for Assessment and Accreditation of Higher Education (A3ES), Lisbon, Portugal

Centre for Research in Higher Education Policies (CIPES), Matosinhos, Portugal

(C) The Author(s) 2022

O. Tavares et al. (eds.), Equity Policies in Global Higher Education, Issues in Higher Education, https://doi.org/10.1007/978-3-030-69691-7_7 
could reduce inequalities in higher education participation (Amaral \& Magalhães, 2009). To this end, over the following decades, polytechnic institutions were established to offer shorter and more vocational higher education programmes and the private sector was allowed to expand to respond to the increasing demand for higher education. However, the experience and the time elapsed have shown that massification, by itself, has been insufficient to solve the problem of inequalities in access to higher education. Despite the expansion of the system and the diversification of the student body, in Portugal there continue to exist differences in transition rates depending on factors such as the type of secondary education attended, socioeconomic status or gender (Domingos et al., 2016). Inequalities in access are closely linked to the cultural and economic factors that are 'hard to convert or recast' (Nata et al., 2014), cumulative in students' educational paths already during non-tertiary education (Buisson-Fenet \& Draelants, 2013; Engberg \& Wolniak, 2010; Frempong et al., 2012; OECD, 2008).

Educational inequalities are deeply embedded in Portugal. Data from the last census conducted in 2011 reveal a fragile situation for the country, with $8.5 \%$ of the population having no schooling at all, $2.5 \%$ with preschool level, $29.8 \%$ with primary education (fourth grade), $26.1 \%$ with middle education (fifth to ninth grade), $17.6 \%$ with secondary education and $15.4 \%$ with higher education. In the same year, the illiteracy rate lay at $5.2 \%$. In order to address this situation, the political agenda for education since the mid-2000s has pursued objectives such as making pre-school education compulsory, diversifying secondary school offerings and providing alternative curricular routes in lower and upper secondary education and making education compulsory until the age of 18 (this latter measure dating from 2012). Similar to other European countries, fighting early educational drop-out became a political priority, manifest in the consolidation of the public sector and in the offer of support to low-income families in order to delay premature entry into the labour market (Amaral et al., 2016).

These political measures appear to have been successful, if OECD data are considered. Regarding upper secondary education, first-time graduation rates below age 25 registered a 'striking' increase of 32 percentage points in Portugal between 2005 and 2015 (from 51 to 83\%), while the average for countries with available data was an increase of 7 percentage points (OECD, 2017, p. 58). These figures stand as evidence both for the great delay from which Portugal had to recover and for the progress 
achieved in a relatively short time-period. According to the most recent comparative data (OECD, 2018), in 2016 upper secondary and postsecondary non-tertiary first-time graduation rates were $80 \%$ in Portugal, compared to $87 \%$ across the OECD and the EU22 countries.

In parallel to non-tertiary education reforms, access to higher education was widened to include new publics. In a context of demographic decline, the higher education system was further diversified through the creation, in 2014, of short-cycle tertiary courses, non-degree-awarding but meant to attract students with a vocational profile or those students who had not obtained satisfactory grades in the national competition for access to higher education, as well as through the promotion of participation in higher education of mature students (over 23 years old). Nevertheless, tertiary attainment in Portugal among 25-64 year-olds is still 24\%, while the OECD average is $30 \%$ and the EU22 average is $29 \%$ (OECD, 2017).

In what follows, a review of the main factors which represent sources of inequality in the transition to higher education is presented. The chapter then moves on to the Portuguese panorama and discusses findings based on DGEEC data on the key aspects which affect transition to higher education: (1) the type of secondary programme attended by the student; (2) students' characteristics; (3) regional differences; (4) secondary schools' internal grades used in the national competition to enter HE. Finally, the chapter concludes with a summary and discussion of inequalities which still need addressing to ensure fairness in access to higher education.

\section{From Secondary to Higher Education: Determinants OF INEQUALITIES}

The literature identifies several factors which influence secondary school graduates' chances of entering higher education (Engberg \& Wolniak, 2010; Marginson, 2016; OECD, 2008; Vossensteyn, 2005). Some of the most commonly mentioned ones are reviewed in this section.

Socioeconomic status is one frequently mentioned determinant for the transition to higher education. According to Marginson (2016, p. 421), 'the principal intrinsic limit to social equality of opportunity is the persistence of irreducible differences between families in economic, social and cultural resources'. Socioeconomic status can influence students' decision whether or not to enrol in higher education (Tavares, 2013), as these 
evaluate the gains and losses of a certain alternative in relation to a reference point and not as absolute results of a decision (Vossensteyn, 2005). Thus, a student from a family with difficult economic conditions will evaluate the costs and benefits of attending higher education based on his/her family's income as a reference point. If the student comes from a family with a high economic status, the evaluation of gains and losses is likely to be different.

Parents' education, as an indicator of socioeconomic status, is influential for students' participation in higher education (Chesters \& Watson, 2013; Cingano, 2014; Marginson, 2016; OECD, 2008; Van de Werfhorst \& Hofstede, 2007). Income inequality and parents' educational capital are related. A comparison across the OECD countries (Cingano, 2014) suggests that a rise in income inequality by 6 Gini points is accompanied by a $4 \%$ decrease in the probability of individuals with parents of low educational background being in tertiary education. According to Van de Werfhorst and Hofstede (2007), children across all social backgrounds are concerned with avoiding downward mobility; hence, there is a strong correlation between having highly educated parents and the desire to obtain university qualifications. According to OECD data collected through the Survey of Adult Skills (PIAAC), parents' education level has a greater impact than age or gender on the likelihood of attaining a theory-based first degree or an advanced research degree (OECD, 2017). Chesters and Watson (2013), in a study in Australia, found that men with a universityeducated father were 2.8 times more likely to have graduated from university than other men and that women with a university-educated father were 3.7 times more likely to have graduated from university than other women.

The comparison between the share of young adults from potentially disadvantaged groups in the overall population and their share among tertiary students is indicative of inequality in higher education (OECD, 2018). For example, a lower share among tertiary students than in the overall population indicates that this demographic group is underrepresented and, therefore, has lower access to higher education. Taking as reference parents' educational attainment, young people whose parents do not have tertiary education are underrepresented among new entrants to bachelor, long first degree or equivalent programmes. On average across OECD countries with available data, these represent $65 \%$ of the population aged 18-24, but only $47 \%$ of 18-24 year-old new entrants. In Portugal, 18-24 year-olds without tertiary-educated parents represent 
$79 \%$ of the total population of that age group, but only $62 \%$ of new entrants (OECD, 2018). Inequality determined by social status is therefore an enduring phenomenon affecting the transition to higher education of young people in OECD countries, Portugal included.

Students with higher academic achievement are more likely to access higher education. The literature often discusses academic achievement in association with socioeconomic status. More precisely, academic achievement is often considered in the literature as influenced by the socioeconomic background (Brynes \& Miller, 2007; Chowdry et al., 2008; Davis-Kean, 2005; Engberg \& Wolniak, 2010; Sirin, 2005). The socioeconomic status of families has been used as the most consistent predictor of academic achievement, because students from privileged socioeconomic backgrounds seem to have access to higher quality secondary education, tutors, test preparation or better schools than students from lower socioeconomic backgrounds have. Lower achievement may therefore be indicative of lower socioeconomic status.

According to Chowdry et al. (2008), students' academic achievements vary significantly by social class by the time they have completed compulsory education. They found that the socioeconomic gap did not emerge at the point of entry to higher education and that almost all the difference at this stage was explained by the fact that poorer pupils did not achieve as highly in secondary school as their more advantaged counterparts (Chowdry et al., 2008). However, other authors point to a stronger effect of social class. Noble and Davies (2009) found that students with lower levels of cultural capital are less likely to apply to higher education even after taking academic attainment into account.

Previous schooling-completion of compulsory education levels, choice of state or private schools as well as the orientation of secondary education, more academic or more vocational-is another factor responsible for variations in transition rates to higher education. Again, schooling background is discussed in association with socioeconomic status in the literature (Buisson-Fenet \& Draelants, 2013; Chowdry et al., 2008; Engberg \& Wolniak, 2010; Frempong et al., 2012; Mangan et al., 2010). Noble \& Davies $(2009$, p. 593$)$ refer to social class effects as also 'operating through school attainment and tracking'. Inequality in entry to higher education may therefore be a reflection of inequalities which have accumulated throughout an individual's educational path (OECD, 2008, 2018). Under-representation of disadvantaged students in tertiary programmes can result from obstacles in entering higher education itself or 
from obstacles that have kept these individuals from progressing at earlier levels. Many disadvantaged students leave the education system before even reaching the point at which they could enter a tertiary programme. OECD data (OECD , 2018) reveal that in most countries potentially disadvantaged students are less likely to advance through education, as the share of students whose parents have lower educational attainment decreases between the moment of entry to upper secondary education, graduation from upper secondary education within the theoretical duration and, finally, the moment of entry to tertiary education.

Attendance of private (or independent) schools-or schools which enrol students with a high socioeconomic status - appears to favour entry to higher education (Chesters \& Watson, 2013; Engberg \& Wolniak, 2010; Mangan et al., 2010). These schools usually enrol students coming from economically advantaged families. For instance, Engberg and Wolniak (2010) found that the average socioeconomic status of a high school proved to be a very strong indicator of higher education enrolment in the United States. Similarly, in Canada, Frempong et al. (2012) reported that young people from disadvantaged socioeconomic backgrounds who attend schools with high concentration of similar students are particularly vulnerable to some degree of exclusion from accessing higher education. These socioeconomic impacts remained statistically significant even after adjustment of other student-level and school-level variables (Frempong et al., 2012).

The obstacles to access higher education can also reflect the nature of students' upper secondary degree (OECD, 2018). The separation between academic and vocational education, known as tracking, can also be responsible for inequality in access to higher education (OECD, 2008). In many countries there are upper secondary programmes that do not grant credentials to enter higher education. This is also the case of Portugal, where vocational and professional tracks do not entitle students to automatically apply for higher education without standing the same national exams as those students who followed more academically-oriented tracks. New legislation is being prepared to address this obstacle.

Gender is also reported in the literature to influence participation in higher education (Richardson et al., 2020). Participation in higher education is generally higher among women, which seems to depend on attainment in previous levels of education (Richardson et al., 2020). Women outperform men, as reported by OECD data (2017), with a $72 \%$ completion rate of upper secondary education among the former, against $64 \%$ for 
the latter. In a study conducted in the UK, the differences in attainment already are obvious at age 14-16 years (Crawford \& Greaves, 2015). This study also noted differences in aspirations between boys and girls.

The spatial distribution of higher education institutions and the availability of higher education near home is another factor which influences enrolment (as well as choice of higher education institution) (Lourenço et al., 2020; Mangan et al., 2010; OECD, 2008; Sá et al., 2004). Students' behaviour and decisions may be guided by 'the distance discouragement effect' (Sá et al., 2004). Students from low socioeconomic groups are, once again, those who are more likely to see their choices restricted by geographical distance (Christie, 2007; Mangan et al., 2010; Parker et al., 2016). They may, for example, prefer to study at a local institution in order to continue living in their family home, to reduce the cost of study or to maintain participation in local social networks (Mangan et al., 2010). However, these disadvantaged candidates often live in areas with fewer educational opportunities, and are less able to meet the costs associated with migration (Parker et al., 2016). In the absence of local higher education provision, students may thus decide against enrolling. In Portugal, the accessibility of higher education is a pertinent issue since Portuguese students are little mobile and the majority of higher education candidates prefer to remain in their home district (Lourenço et al., 2020).

Transition to higher education can also be affected by selection and admission procedures. The case of internal secondary school grades, particularly in comparison to national exam scores, is discussed here. This discussion is pertinent for the chapter because internal grades and national exam scores are the two elements which contribute to the calculation of the score which counts for selection and entry to higher education in Portugal. Most candidates apply to higher education through a national and centralised competition in which they have to rank their top six preferences of a programme/institution. Their score is the decisive element for the distribution of higher education places.

Generally, there tends to exist a systematic difference between internal grades and national exam scores, as the former also explicitly value homework and behaviour in class, for instance, besides academic performance. Further systematic differences can be explained both by factors affecting internal grades, such as pressures for high-grading or the use of grades as a class management tool, and by annual variations of the national exams' difficulty level, as measured by sometimes significant variations of the national average scores. 
The aforementioned factors, however, can have serious implications for the equity of the national competition to access higher education if they affect schools differently. In particular, since both the pressure for high grading and the school's response to it can be very uneven across the system, internal grades can be much higher in some schools than in others, for students who otherwise have similar exam scores. According to Wikström (2005), the schools which are subject to market pressure are more likely to attribute higher grades. This is mostly the case of private schools, striving to offer a competitive advantage to their 'customers' in a context of marketization of education (Ball, 2009). Recent longitudinal research conducted in Portugal found that independent private schools, on average, inflate their students' grades when compared to public and to government-dependent private schools, although this a fairly localised phenomenon observed mostly in schools situated in the northwest region of continental Portugal (Mestre \& Baptista, 2016a; Nata et al., 2014). Grade-inflation is understood in these studies as the deviations from the average differential between internal grades and scores in national exams, which represents the baseline. These findings therefore raise a question mark about the fairness of access to higher education and the maintenance of social inequalities through this mechanism (Nata et al., 2014; Neves et al., 2017).

\section{Inequalities in Access to Portuguese Higher EDUCATION}

This section presents and discusses the findings regarding inequalities present already before higher education and inequalities in the transition to higher education.

\section{Inequality in Secondary Education Participation}

The two main types of upper secondary education in Portugal, in number of enrolled students, are the scientific-humanistic and the vocational education programmes. Students also enrol in other variants such as artistic education, technological education and apprenticeships, but in much smaller numbers. For instance, in 2017/18, scientific-humanistic programmes, the traditional qualification of those aspiring to enter higher education, accounted for about $60 \%$ of upper secondary graduates, while 
vocational programmes represented around one third of graduates. Female graduates represented the majority in scientific-humanistic and artistic programmes $(58 \%$ and, respectively, $72 \%)$, while male graduates represented the majority in vocational and technological programmes $(54 \%$ and, respectively, $52 \%$ ).

The population of graduates from Portuguese upper secondary education, however, does not mirror the population of the general age cohort. Its composition is quite different from the population of students enrolled in the more universal basic education, with students from disadvantaged socioeconomic backgrounds, as well as boys, being severely underrepresented among upper secondary graduates. This is especially true for graduates in secondary scientific-humanistic programmes, the main recruitment pool for higher education institutions. It is worth noting how the proportion of female students increases as the level of education goes up. Considering $2017 / 18$, females represented $48.1 \%$ of students in the last years of lower secondary education (age 12-14), while in scientifichumanistic programmes they amounted to $54.8 \%$. Among the graduates of these programmes (age 17), the percentage of female students went up to $58.3 \%$.

In parallel with the gradual reduction of the percentage of male students, a similar phenomenon takes place with students who benefit from social support. While in the last years of lower secondary education (age 12-14) these latter represented $36 \%$ of the student body, their proportion went down to $24 \%$ in upper secondary scientific-humanistic programmes and, among graduates from these programmes, they only represented $21 \%$. An explanation for this downward trend is that students from disadvantaged socioeconomic backgrounds navigate through lower secondary education with significantly lower academic performance and lower grades, on average, than other students do (Mestre \& Baptista, 2016b). This contributes to different programme choices (vocational versus scientific-humanistic) and different drop-out rates during upper secondary education.

Our main point, thus, is that there exists a strong socioeconomic filter during upper secondary education in Portugal, with roots traceable to different academic performances in basic and lower secondary education. This filter creates a severe imbalance in the population of graduates of secondary scientific-humanistic programmes - the students in the best conditions to enter higher education. The correlation between socioeconomic status and academic performance then appears to become milder 
during higher education itself (Engrácia \& Baptista, 2018), which raises the hypothesis that the minority of disadvantaged students that reach higher education forms a group of resilient "academic survivors" that, with the help of existent social support, on average does reasonably well during higher education. In Portuguese higher education, thus, most social inequity happens before crossing its gates.

\section{Inequality in Transition from Secondary to Higher Education}

The transition rates to HE depend on two main factors: the type of secondary education attended and students' characteristics. Additionally, in Portugal, students' region of origin also influences transition to HE.

\section{Type of Secondary Education}

The track of secondary education from which students graduate conditions their likelihood of enrolling in higher education. Considering the cohort who graduated from upper secondary education in 2017/18, $80 \%$ of graduates from scientific-humanistic programmes were enrolled in higher education one year later, and almost all at the bachelor's or integrated master's level. In contrast, only $18 \%$ of those who graduated from secondary vocational programmes were enrolled in higher education after one year, two thirds of which in short-cycle programmes. In the case of technological and artistic education graduates, HE enrolments amounted to $58 \%$ and, respectively, $57 \%$. These transition rates to $\mathrm{HE}$ have been very stable over the past decade.

As for the nature (public or private) of the high-school attended, once the comparison is made separately for scientific-humanistic and vocational programmes, the transition rates to $\mathrm{HE}$ after one year were very similar for public and private school graduates in 2014/15. One must bear in mind, however, that the relative similarity is true only for graduates, not for the general enrolled students, since graduation rates are lower in public secondary schools than in private ones, an expression of the socioeconomic filter alluded to in the last section.

\section{Students' Characteristics}

Students' characteristics also condition transition rates to higher education. Gender, social-economic status and previous academic results are the 
characteristics chosen to illustrate their influence on transition to $\mathrm{HE}$, considering the two main types of upper secondary education graduates: those from scientific-humanistic programmes, and those from vocational programmes. Regarding gender, transition rates to higher education are similar for male and female graduates in scientific-humanistic programmes ( $83 \%$ and $84 \%$, respectively). However, since there are more female graduates in these programmes (which are the privileged path to $\mathrm{HE}$ ), in the end more women go into higher education. In vocational programmes, in contrast, the percentage of male students transitioning to higher education is slightly higher ( $20 \%$ compared to $17 \%$ for women).

Regarding socioeconomic status, using social support as a proxy, the evidence, as expected, is that the stronger the level of support, the lower the proportion of graduates that pursued higher education studies in $2014 / 15$, both in scientific-humanistic programmes and in vocational programmes. This is illustrated by Fig. 7.1, comprising graduates of public high-schools only.

This suggests that it is more difficult for students with a lower socioeconomic status to enter higher education. This first level of inequity, however, is greatly reinforced by the fact that disadvantaged students disproportionately enrol in vocational programmes, which, as shown above, have much lower transition rates into higher education.

Using a different proxy for socioeconomic status, the mother's school level, a similar phenomenon is observed in the transition to higher education: the lower the mother's educational level, the lower the proportion of

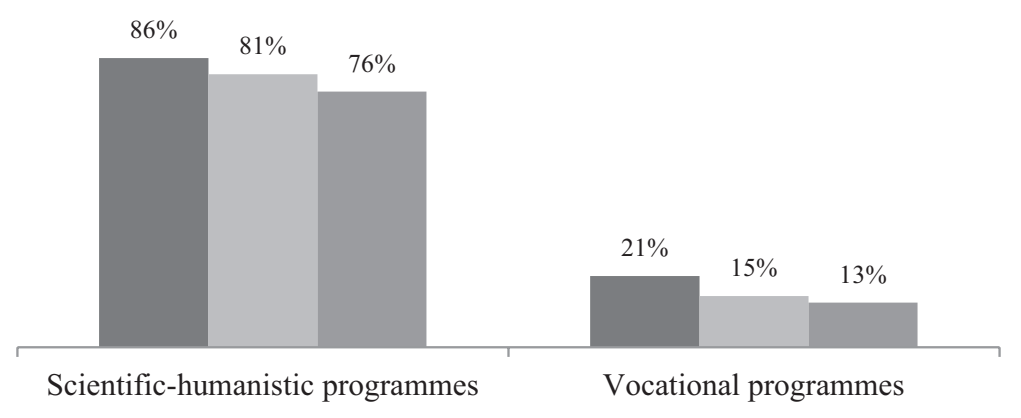

$\square$ No support $\square$ Medium level support $\square$ Strong level of support

Fig. 7.1 Secondary education graduates that pursued further studies (\%), by type of secondary programme and level of social support, in 2014/15 


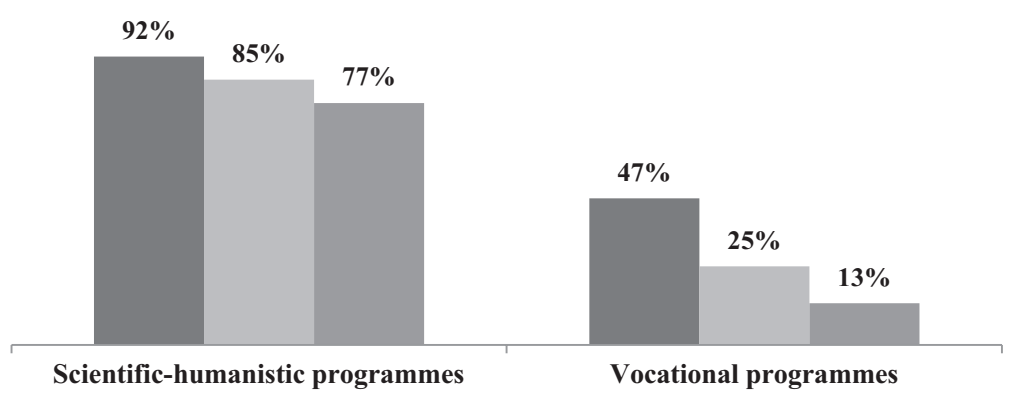

घhigher education $\square$ Lower or upper secondary education $\quad$ Basic education, until grade 6

Fig. 7.2 Secondary education graduates that pursued further studies (\%), by type of secondary programme and mother's school level

secondary education graduates who pursued further studies in 2014/15 (see Fig. 7.2). Having a mother with higher education makes a big difference in the probability to study further, especially for students graduating from vocational programmes, as $47 \%$ pursue further studies in this case compared to $13 \%$ in the case of graduates whose mothers have basic education only. Once again, one should bear in mind that this effect, shown here within each secondary programme, is reinforced by the fact that students whose mothers have low educational level disproportionately enrol in vocational programmes.

Previous school results are the last factor considered here that heavily influences transition rates to higher education. Since it is not easy to have a comparable measure of student academic performance across all different programmes in Portuguese upper secondary education (some programmes have national exams, while others do not, or have different exams), the measure used here is the score obtained by the graduate three years earlier, on the national exams of Mathematics and Portuguese of the ninth grade. Since most students now enrolled in upper secondary education, scientific-humanistic or vocational, have done these two exams in the past, their scores can be used as a standard for previous academic performance. With this clarification in mind, the evidence is that, as expected, the better the results obtained by secondary graduate in the ninth grade exams, the higher their rates of enrolment in higher education (see Fig. 7.3). 


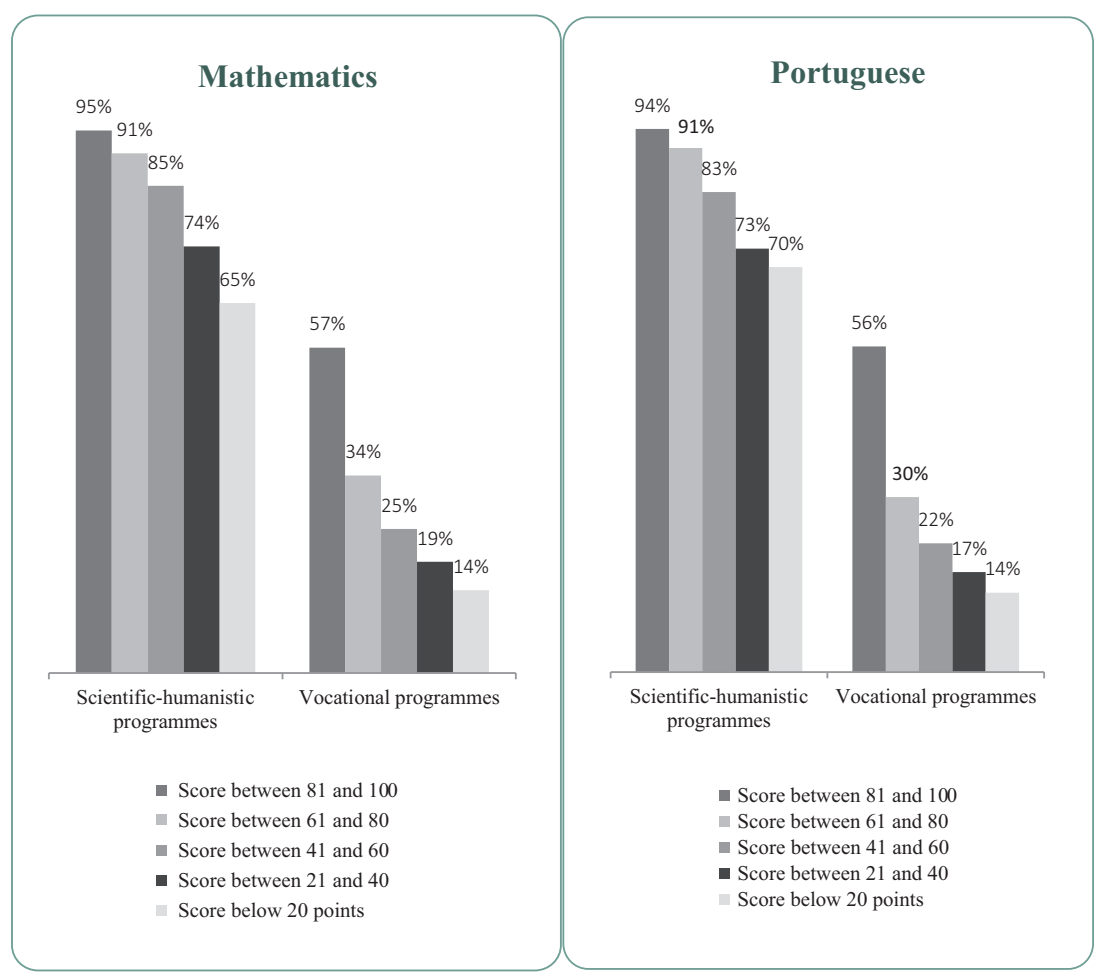

Fig. 7.3 Secondary education graduates that pursued further studies (\%), by type of secondary programme and score obtained 3 years earlier in the national exams

It is worth noting, however, that all groups of graduates of vocational programmes have lower transition rates to higher education than their scientific-humanistic peers. Even the vocational graduates who scored very high in the national exams at the end of the ninth grade, three years before, have lower transition rates to higher education than the scientifichumanistic graduates that scored low in the same exams.

This big difference between vocational and scientific-humanistic graduates could happen for two kinds of reasons, whose relative weight is difficult to measure. A first reason is that there are some system barriers to transition from vocational secondary education to higher education in Portugal. One such barrier is the fact that the admission exams to bachelor 
HE coincide with national exams of the scientific-humanistic curricula, which means that graduates from vocational programmes have less preparation to take those admission exams than their scientific-humanistic peers do. Another barrier is the fact that short-cycle higher education, although clearly open to vocational education graduates, is still recent in Portugal, still growing and not yet widely known by students or offered by higher education institutions. A second reason is the presumed lower interest of vocational education graduates in pursuing higher education. Students who choose vocational programmes at the beginning of upper secondary education are less inclined to pursue academic-style studies, on average, than their colleagues that enrol in scientific-humanistic programmes, even if they have high grades. Hence, not pursuing academic higher education at the end of secondary education is a decision quite consistent with the students' previous preferences and choices.

\section{Regional Differences}

Portugal has a fairly distributed network of HEIs across the territory. The expansion of the Portuguese higher education system contemplated the existence of either a university or a polytechnic institution in the different Portuguese regions, so that these would be easily accessible to local secondary school graduates. However, there are clear differences in the transition rates to higher education among upper secondary graduates from distinct Portuguese regions, especially in the case of graduates of secondary vocational programmes.

Besides socioeconomic and labour market regional asymmetries, which are important but apparently insufficient factors to account for the full effect, a plausible explanation for the widely different transition rates is that available places in higher education programmes and institutions are not equally accessible to local students throughout the country. This can be aggravated by students' unwillingness or inability to move across the country or to pay the fees of a private HEI, a reality likely to be stronger among students with lower socioeconomic status or motivation to pursue $\mathrm{HE}$, such as graduates from secondary vocational programmes, on average. This would help explain why transition rates to $\mathrm{HE}$ show more regional asymmetries for vocational graduates than for scientific-humanistic graduates (Fig. 7.4).

But why are places in higher education not equally accessible to local vocational graduates throughout the country? Firstly, the ratio of local HE 


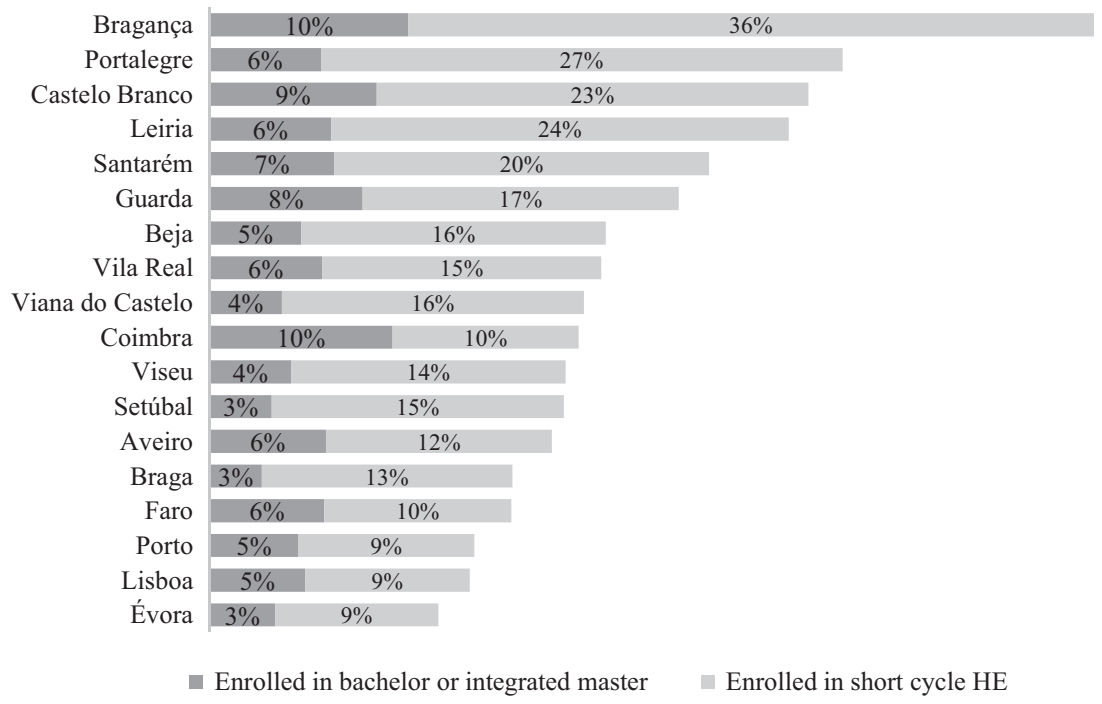

Fig. 7.4 Graduates from secondary vocational programmes that pursued HE studies after 1 year, by district of secondary school, 2017/18

vacancies per local secondary education graduate is not entirely homogeneous, having significant variations across regions, as explored in the chapter by Sá, Tavares and Sin. Secondly, for a number of reasons, public HEIs in Lisbon, Porto and near the northwest coast tend to be considered more attractive by students. These HEIs tend to receive more applications per open vacancy than HEIs in southern and inland continental Portugal. It is therefore more difficult, on average, to be accepted there as a student, and so local vocational graduates from the "attractive" regions can be partially crowded out by students coming in from other regions. Should they be unwilling or unable to move to another region or pay the fees of a local private HEI, these graduates may not go to $\mathrm{HE}$ at all. This would help to explain why vocational graduates from the regions of Lisbon and Porto generally appear to have comparatively lower transition rates to HE.

For vocational graduates, there is an additional reason for the regional differences in transition rates to HE: the lack of available public offer of short-cycle tertiary programmes in certain regions. As seen in the graph, the lowest transitions rates to $\mathrm{HE}$ are observed in the regions of Évora, Lisbon and Porto. Évora has no public polytechnic institution and no 
offer of public short-cycle tertiary programmes. Lisbon has a large public polytechnic, but it decided not to offer short-cycle tertiary programmes. Porto has a large public polytechnic, but for several years, it scarcely offered short-cycle tertiary programmes, and has only recently started offering them in greater numbers. As a result, vocational secondary education graduates from these regions who wish to continue in the vocational track and pursue short-cycle tertiary education face the following choices: enrol in a local private institution, which will be more expensive; move to another region to pursue short-cycle HE (more expensive and inconvenient); or apply to a bachelor programme in their region, in which it will be more difficult to be accepted and which will possibly not match their vocational profile. As figures indicate, faced with these choices, vocational graduates from Lisbon, Porto and Évora also seem to renounce pursuing higher education at higher rates than graduates from other regions do.

\section{Internal Grades}

Among the new entrants to higher education in Portugal each year, a majority of young students use the so-called national competition to enter bachelor-level programmes. In this competition, candidates apply to a maximum of six pairs programme/institution of their choice. If there are more candidates than vacancies, candidates are selected using a score (scale 0-20) based on two components: school grades in upper secondary education and scores in national exams in programme-related subjects. These two components have approximately the same weight in the final ranking score to enter higher education, although the precise weights can vary. For the seriation score to be fair, it is important that different secondary schools use approximately the same criteria when attributing internal grades to their students.

However, there is evidence to suggest that some schools tend to give more "generous" grades than others, systematically, for students with comparable ability, as measured by scores in the national exams. As documented by previous research, for instance private schools in northwest Portugal, in the regions of Porto and Braga, tend to attribute higher internal grades than most other schools to students with similar performance in the national exams (Mestre \& Baptista, 2016a; Nata et al., 2014; Neves et al., 2017). This may give their students a systematic and unfair edge in the national competition to enter HE. Since these students generally come from privileged socioeconomic backgrounds, these differences in internal 
school grade reinforce social inequalities in access to higher education. Fig. 7.5 is illustrative of the mismatch of internal grades for students with the same scores in national exams, in different types of schools. The average size of the mismatch varies between 0.5 and 0.8 points in a grade scale from 0 to 20 , with higher grades in private schools.

Although the preceding graph shows national averages, the phenomenon of grade inflation in Portugal is fairly localised in the northwest region of the country, especially in schools around Porto and Braga, where it has propagated also to public schools, albeit on a smaller scale (Fig. 7.6). The local propagation is easy to understand: as the "generous" secondary schools tend to attract the enrolment of an increasing number of students from the region, in search of the "edge", other local schools feel strongly compelled to follow the same strategy, in order not to lose students and not to put them at a disadvantage to enter HE, thus generating a local "grade race". The increased control of grade inflation by the Ministry of Education since 2015 has had a visible, though still insufficient, effect in the observed scale of the phenomenon.

Besides significant regional and public/private misalignment in the attribution of internal grades, the data also evidences that slightly different criteria may be used in attributing internal grades to students of different socioeconomic status. More precisely, on average, students who receive higher levels of social support tend to be given lower internal grades, when

Avg mismatch

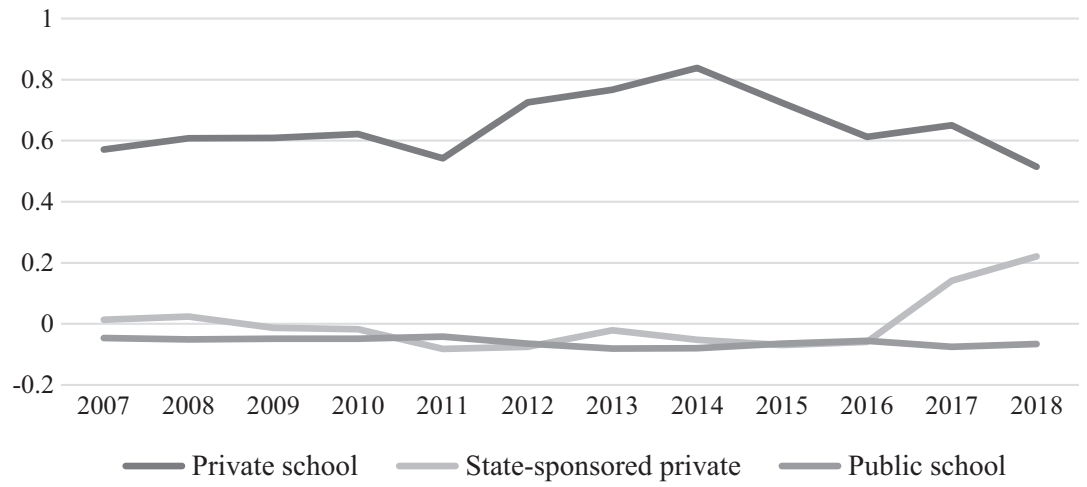

Fig. 7.5 Mismatch of internal grades (scale 0-20) for students with the same scores in the national exams, by type of secondary school 
Avg mismatch

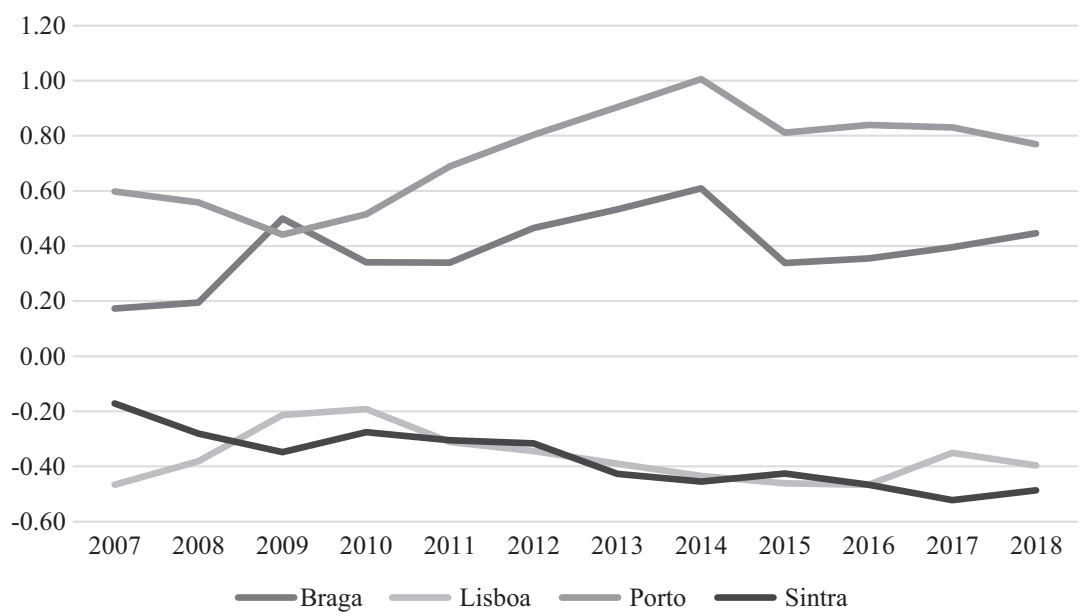

Fig. 7.6 Mismatch of internal grades (scale 0-20) for students with the same scores in the national exams, by municipality

compared to their higher status peers that have similar scores in the national exams. The graph below (Fig. 7.7) illustrates this mismatch of internal grades for students with different levels of social support enrolled in public high schools. The magnitude of the effect is small (about 0,2 points in the scale of grades from 0 to 20 ), but quite stable in time.

At least four plausible, non-exclusive, explanations can be advanced for the observed mismatch of internal grades attributed to students of different socioeconomic backgrounds:

1. Teachers' academic expectations for students may (involuntarily) be influenced by the student's socioeconomic background, and different expectations can lead to different grading criteria through a confirmation bias.

2. Higher status parents may be more vocal or effective in pressuring teachers into being more "generous".

3. Internal grades are different from national exams scores, in the sense that they also value homework and behaviour in class, for instance, besides academic performance. The difference in grades between 
Avg mismatch

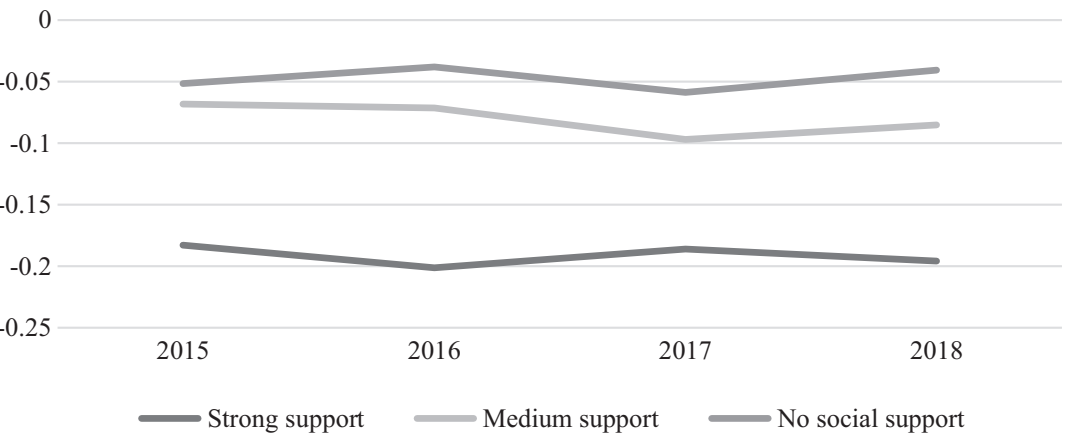

Fig. 7.7 Mismatch of internal grades (scale 0-20) for students with the same scores in the national exams, by level of student social support-public schools

lower and higher status students can thus come from the behavioural components of the internal grade.

4. Not all public schools have the same criteria for attributing internal grades. Being more mobile and informed, higher status students may seek and enrol more often in the "generous" schools, thus benefiting from its "generous" grades.

Unfortunately, we do not have data about expectations, parents' pressure or student behaviour in class in Portuguese public schools to empirically test the explanatory power of the first three hypotheses. The first two explanations seem entirely out of reach of a methodology based on the analysis of data registered by schools on national databases. As for the third explanation, it could in principle be tested through more readily available, or at least collectable, data on student (mis)behaviour in class. Bear in mind, however, that when comparing data of high and low socioeconomic status students, one should compare students with similar levels of academic performance (for instance, with similar scores on national exams). Once this condition is imposed, it is no longer obvious that lower status students will, on average, be more misbehaved or show less interest in class.

Finally, regarding the fourth explanation, we do seem to have enough data to exclude that it plays a major role in the reported internal grade mismatch. In fact, if the main cause of the mismatch were that high status 


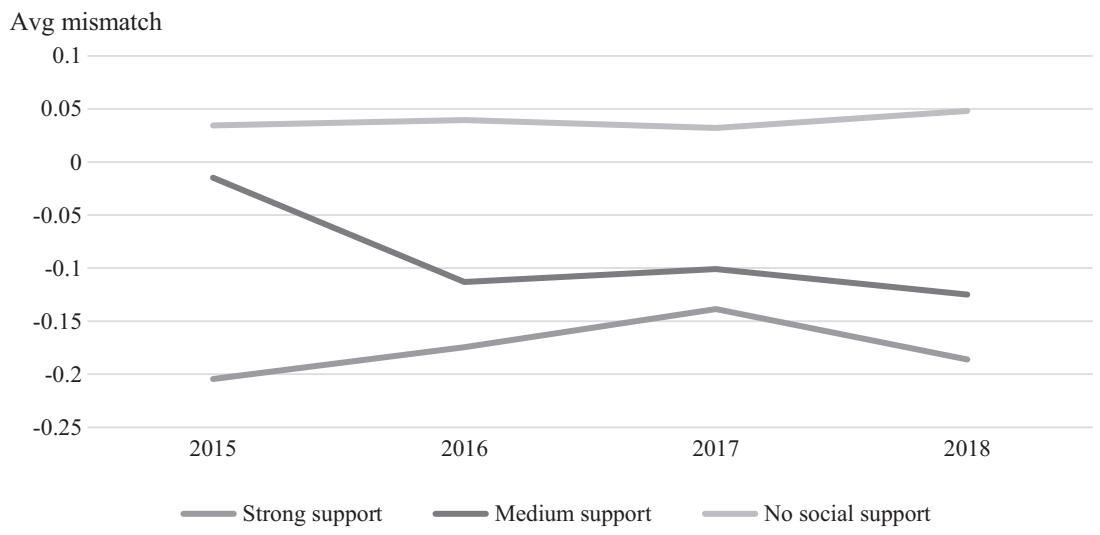

Fig. 7.8 Mismatch of internal grades (scale 0-20) for students of the same school with the same scores in the national exams, by level of social support-public schools

students attend more "generous" public schools, on average, than low status students, then one should not observe any significant internal grade mismatch within the same school, only between different schools. This is not the case, however: comparing the internal grades attributed to students of different socioeconomic backgrounds that obtained similar scores in the national exams and are enrolled in the pery same school, we observe that the internal grade mismatches are still present, being even slightly stronger. Averaging the internal mismatches over all public schools in continental Portugal, one obtains the data depicted in Fig. 7.8.

\section{CONCLUSION}

This chapter analyses inequalities in the transition from upper secondary to higher education in Portugal, resorting to an analysis of national data of the General-Directorate of Education and Science Statistics (DGEEC). The central argument of this chapter is that socioeconomic status is the most important aspect that directly or indirectly conditions transition to higher education in Portugal, and thus is the primary source of inequality in participation. The socioeconomic filter is measurable at the moment of transition to higher education, through different transition rates among upper secondary graduates coming from distinct socioeconomic 
backgrounds. However, this filter acts at its strongest a few years earlier, during secondary education itself, when different levels of academic achievement and different choices of educational tracks heavily condition the probability of disadvantaged students to graduate and adequately compete with their peers for entrance in the higher education system.

The findings also point to other factors similar to those already highlighted in the literature as responsible for inequalities in access to higher education: previous schooling, gender, different regional opportunities and selection and admission criteria, with socioeconomic status appearing to be transversal to and/or aggravate the influence of most of these other factors (except gender).

As in other countries, previous schooling influences transition rates to higher education. The socioeconomic filter in upper secondary education has origins in students' trajectories and academic performance in basic and lower secondary education, with tracking playing an important role. In Portugal there are two main tracks in secondary education, the scientifichumanistic and the vocational, the latter having much lower transition rates and being mainly chosen by students from lower socioeconomic backgrounds.

In the transition to higher education, the weight of socioeconomic status is visible when using the social support from which students benefit as a proxy for socioeconomic status. Data shows that the higher the social support students have, the lower their enrolment rates in higher education are. The effect of socioeconomic status is also visible using as proxy the education level of the students' mother. The higher the educational level of students' mothers is, the higher their enrolment rates in higher education are. Previous academic achievement, related in the literature to socioeconomic status, also conditions transition rates: the better the results obtained by secondary graduates in the ninth grade exams, the higher their rates of enrolment in higher education. We also observed, however, that the vocational graduates that scored high in the ninth grade exams, three years before, have lower transition rates to higher education than the scientific-humanistic graduates that scored low in the same exams. It seems, therefore, that the general correlation between low socioeconomic status and low academic achievement, as a barrier to enter higher education, is compounded by the fact that disadvantaged students disproportionately enrol in vocational programmes, which have much lower transition rates into higher education. 
Students' socioeconomic status appears to be closely intertwined with the other factors influencing transition to higher education. One such factor is the type of secondary school attended by students. While public schools enrol students of all socioeconomic levels, private schools in the scientific-humanistic track tend to enrol students from families with a high socioeconomic status. Although transition rates to higher education are similar for scientific-humanistic graduates of both public and private schools, inequality remains present because public schools have lower graduation rates than private ones.

There is also evidence that some schools tend to give more "generous" internal grades than others, systematically, for students with comparable ability, as measured by scores in the standardised national exams, thus potentially offering an additional advantage to their graduates in the national competition to enter higher education. This phenomenon is not random with respect to region and socioeconomic background, as it appears to be especially concentrated in private schools in the northwest region of Portugal, which seem to be using high grades as a tool to attract local students of privileged backgrounds. With a much smaller effect size, there is also evidence that, even within the same school, students of higher socioeconomic backgrounds tend to be given higher internal grades than their lower status peers who, otherwise, score similarly in the national exams. This could be a consequence of different academic expectations that teachers involuntarily may have for each type of student, through a confirmation bias, or could be explained by a higher effectiveness of high status parents in pressuring teachers into being relatively benign with their child, but the data and methodology used do not allow testing the different hypotheses. In any case, the internal grade mismatches do seem to be reinforcing the disadvantages of low status students when trying to access higher education.

Finally, the regional asymmetries observed in the transition to higher education are also indicative of socioeconomic inequalities, since the differences are related, at least in part, to the availability of tertiary education provision in the vicinity of the place of residence (OECD, 2008, p. 45), which has a bigger impact in the (comparatively less mobile) population of disadvantaged students. The observed regional differences in transition rates to higher education are higher in the case of graduates of vocational tracks, who tend to come from more disadvantaged backgrounds. These students are less likely to be willing or able to move across the country or 
to pay the fees of a private HEI, thus further reducing their chances of attending higher education.

To sum up, in Portugal, inequalities begin much earlier than the moment of transition to higher education, as socioeconomic status plays a major role in students' educational progress and choices throughout their trajectories. Disadvantaged students who manage to surmount all the different obstacles and reach higher education belong to a group of resilient "academic survivors". Future research could explore the characteristics of these academic survivors in order to inform policies that could foster the enlarged participation of students from low socioeconomic backgrounds.

Based on the findings of this study, several areas of intervention could be proposed. First, and most importantly, the strong socioeconomic bias of academic achievement now observed during lower and upper secondary education should be addressed and mitigated as a precondition to obtain an equitable access to higher education. Second, in order to increase education levels of the Portuguese population, since parents' education influences rates of enrolment in higher education, there should be continued investment in and promotion of lifelong learning. Third, regarding the regional asymmetries in the transition to higher education, the territorial coverage of public short-cycle tertiary education should be reinforced in regions that are presently underserved, such as Évora, Lisbon and Porto, where graduates of vocational secondary education have the lowest transition rates to $\mathrm{HE}$. A more balanced regional ratio of $\mathrm{HE}$ places per secondary education graduate could also be envisaged, including perhaps the allocation of a small regional quota for local students.

Finally, in order to control grade inflation and avoid that some students from privileged backgrounds are given an unfair "edge" in the competition for higher education places, several possibilities could be considered. Firstly, the ministry of education, besides monitoring the phenomenon, could make more forceful interventions to discipline the small number of transgressing schools, because unbounded school autonomy in grading is not compatible with general fairness and equity. A second possibility would be that the national competition for higher education, on its own initiative, stops accepting as equally valid grades attributed by schools with a proven track record of grade inflation. The competition could announce that, from now on, students that enrol in schools that systematically exceed a given limit of grade inflation, may have their internal grades readjusted, according to a transparent formula, for the purpose of calculating final scores for entry in HE. As in other countries, a third possibility would be 
to establish, for all students, a more elaborate formula to calculate the final scores for entry in HE, a formula that would involve, besides the student's school and exam grades, also corrective coefficients for the student's percentile within the class and the observed level of internal grade mismatch within the class.

\section{REFERENCES}

Amaral, A., \& Magalhães, A. (2009). Between Institutional Competition and the Search for Equality of Opportunities: Access of Mature Students. Higher Education Policy, 22(4), 505-521.

Amaral, A., Magalhães, A., Caramelo, J., Cardoso, S., Rocha, C., Sin, C., Tavares, O., Vaz, H., Veiga, A., \& Videira, P. (2016). Que perceções têm os portugueses sobre o valor da educação? Edulog, FundaçãoBelmiro de Azevedo.

Ball, S. J. (2009). Privatising Education, Privatising Education Policy, Privatising Educational Research: Network Governance and the 'Competition State'. Journal of Education Policy, 24(1), 83-99.

Brynes, J. P., \& Miller, D. C. (2007). The Relative Importance of Predictors of Math and Science Achievement: An Opportunity-Propensity Analysis. Contemporary Educational Psychology, 32(4), 599-629.

Buisson-Fenet, H., \& Draelants, H. (2013). School-Linking Processes: Describing and Explaining Their Role in the Social Closure of French Elite Education. Higher Education, 66(1), 39-57.

Chesters, J., \& Watson, L. (2013). Understanding the Persistence of Inequality in Higher Education: Evidence from Australia. Journal of Education Policy, $28(2), 198-215$.

Chowdry, H., Crawford, C., Dearden, L., Goodman, A., \& Vignoles, A. (2008). Widening Participation in Higher Education: Analysis Using Linked Administrative Data. Institute for Fiscal Studies. Retrieved March 11, 2020, from http://www.ifs.org.uk/publications.php?publication_id=4234

Christie, H. (2007). Higher Education and Spatial (Im)Mobility: Nontraditional Students and Living at Home. Environment and Planning A, 39(10), $2445-2463$.

Cingano, F. (2014). Trends in Income Inequality and Its Impact on Economic Growth. OECD Social, Employment and Migration Working Papers, No. 163. OECD.

Crawford, C., \& Greaves, E. (2015). Socioeconomic, Ethnic and Gender Differences in HE Participation. BIS Research Paper No. 186. Retrieved from Department for Business Innovation and Skills website: https://assets.publishing.service. gov.uk/government/uploads/system/uploads/attachment_data/ file/474273/BIS-15-85-socioeconomic-ethnic-and-gender-differences.pdf 
Davis-Kean, P. E. (2005). The Influence of Parent Education and Family Income on Child Achievement: The Indirect Role of Parental Expectations and the Home Environment. Journal of Family Psychology, 19(2), 294-304.

Domingos, A., Mestre, C., \& Baptista, J. (2016). Transição entre o Secundário e o Superior. DGEEC - Estudos sobre Educação. Direção-Geral de Estatísticas da Educação e Ciência.

Engberg, M. E., \& Wolniak, G. C. (2010). Examining the Effects of High School Contexts on Postsecondary Enrollment. Research in Higher Education, 51(2), 132-153.

Engrácia, P., \& Baptista, J. (2018). Percursos no ensino superior: situação após quatro anos dos alunos inscritos em licenciaturas de três anos. DGEEC - Estudos sobre Ensino Superior. Direção-Geral de Estatísticas da Educação e Ciência.

Frempong, G., Ma, X., \& Mensah, J. (2012). Access to Postsecondary Education: Can Schools Compensate for Socioeconomic Disadvantage? Higher Education, $63(1), 19-32$.

Lourenço, D., Sá, C., Tavares, O., \& Cardoso, S. (2020). Enrolling in Higher Education: The Impact of Regional Mobility and Public-Private Substitution Effects. Journal of Economic Issues, 54(1), 183-197.

Mangan, J., Hughes, A., Davies, P., \& Slack, K. (2010). Fair Access, Achievement and Geography: Explaining the Association Between Social Class and Students' Choice of University. Studies in Higher Education, 35(3), 335-350.

Marginson, S. (2016). The Worldwide Trend to High Participation Higher Education: Dynamics of Social Stratification in Inclusive Systems. Higher Education, 72(4), 413-434.

Mestre, C., \& Baptista, J. (2016a). Comparação das classificações internas no ensino secundário. DGEEC - Estudos sobre Educação. Direção-Geral de Estatísticas da Educação e Ciência.

Mestre, C., \& Baptista, J. (2016b). Desigualdades socioeconómicas e resultados escolares - $3 .{ }^{\circ}$ ciclo do ensino público geral. DGEEC - Estudos sobre Educação. DireçãoGeral de Estatísticas da Educação e Ciência.

Nata, G., Pereira, M. J., \& Neves, T. (2014). Unfairness in Access to Higher Education: A 11-Year Comparison of Grade Inflation by Private and Public Secondary Schools in Portugal. Higher Education, 68(6), 851-874.

Neves, T., Ferraz, H., \& Nata, G. (2017). Social Inequality in Access to Higher Education: Grade Inflation in Private Schools and the Ineffectiveness of Compensatory Education. International Studies in Sociology of Education, 26(2), 190-210.

Noble, J., \& Davies, P. (2009). Cultural Capital as an Explanation of Variation in Participation in Higher Education. British Journal of Sociology of Education, $30(5), 591-605$.

OECD. (2008). Thematic Review of Tertiary Education: Synthesis Report, Tertiary Education for the Knowledge Society (Vol. 2). OECD. 
OECD. (2017). Education at a Glance 2017: OECD Indicators. OECD Publishing. https://doi.org/10.1787/eag-2017-en

OECD. (2018). Education at a Glance 2018: OECD Indicators. OECD Publishing. https://doi.org/10.1787/eag-2018-en

Parker, P. D., Jerrim, J., Anders, J., \& Astell-Burt, T. (2016). Does Living Closer to a University Increase Educational Attainment? A Longitudinal Study of Aspirations, University Entry, and Elite University Enrolment of Australian Youth. Journal of Youth and Adolescence, 45(6), 1156-1175.

Richardson, J. T., Mittelmeier, J., \& Rienties, B. (2020). The Role of Gender, Social Class and Ethnicity in Participation and Academic Attainment in UK Higher Education: An Update. Oxford Review of Education, 46(3), 346-362.

Sá, C., Florax, R. J., \& Rietveld, P. (2004). Determinants of the Regional Demand for Higher Education in the Netherlands: A Gravity Model Approach. Regional Studies, 38(4), 375-392.

Sirin, S. R. (2005). Socioeconomic Status and Academic Achievement: A MetaAnalytic Review of Research. Review of Educational Research, 75(3), 417-453.

Tavares, O. (2013). Routes Towards Portuguese Higher Education: Students' Preferred or Feasible Choices? Educational Research, 55(1), 99-110.

Van de Werfhorst, H. G., \& Hofstede, S. (2007). Cultural Capital or Relative Risk Aversion? Two Mechanisms for Educational Inequality Compared. The British Journal of Sociology, 58(3), 391-415.

Vossensteyn, J. J. (2005). Perceptions of Student Price-Responsiveness: A Behavioural Economics Exploration of the Relationships Between Socioeconomic Status, Perceptions of Financial Incentives and Student Choice (PhD dissertation). University of Twente, Enschede.

Wikström, C. (2005). Grade Stability in a Criterion-Referenced Grading System: The Swedish Example. Assessment in Education: Principles, Policy \& Practice, $12(2), 125-144$. 
Open Access This chapter is licensed under the terms of the Creative Commons Attribution 4.0 International License (http://creativecommons.org/licenses/ by $/ 4.0 /)$, which permits use, sharing, adaptation, distribution and reproduction in any medium or format, as long as you give appropriate credit to the original author(s) and the source, provide a link to the Creative Commons licence and indicate if changes were made.

The images or other third party material in this chapter are included in the chapter's Creative Commons licence, unless indicated otherwise in a credit line to the material. If material is not included in the chapter's Creative Commons licence and your intended use is not permitted by statutory regulation or exceeds the permitted use, you will need to obtain permission directly from the copyright holder. 